\title{
Isolation of FAP Cells from Mouse Dystrophic Skeletal Muscle Using Fluorescence Activated Cell Sorting
}

Nicoletta Cordani ${ }^{1,2}$, Viviana Pisa ${ }^{3}$, Laura Pozzi ${ }^{1}$ and Clara Sciorati ${ }^{4 *}$

${ }^{1}$ Scientific Institute, Lecco, Italy; ${ }^{2}$ Department of Health of Science, University of Milano-Bicocca, Monza, Italy; ${ }^{3}$ Department of Biomedical and Clinical Sciences, University of Milano, Milan, Italy; ${ }^{4}$ Division of Regenerative Medicine, Ospedale San Raffaele, Milan, Italy

*For correspondence: sciorati.clara@hsr.it

[Abstract] A population of muscle resident CD45-, CD31- cells expressing the mesenchymal PDGF receptor alpha (PDGFR $\alpha$ ) as well as Sca-1 was first isolated in healthy mouse muscles in Uezumi et al. (2010). In the same year, Joe et al. (2010) identified and purified fibro-adipogenic precursors (FAPs), cells located into the interstitial space between myofibers close to vessels, negative for CD45, CD31, $\alpha 7$-Integrin, but expressing CD34, Sca-1.

Both groups demonstrated that these cells are not myogenic in vitro or in vivo, but they are capable of differentiating in vitro towards both fibrogenic and adipogenic lineage (Uezumi et al., 2011). Further marker analysis indicates that the two groups identified independently the same cell population (Natarajan et al., 2010).

FAPs are an important source of fibrosis and adipogenesis in dystrophic skeletal muscle (Natarajan et al., 2010; Cordani et al., 2014). We have recently demonstrated that Nitric Oxide regulates FAP fate inhibiting in vitro their differentiation into adipocytes. In $m d x$ mice, an animal model of DMD, fed with a diet containing the nitric oxide donating drug, Molsidomine, the number of PDGFR $\alpha^{+}$cells was reduced as well as the deposition of both skeletal muscle fat and connective tissues (Cordani et al., 2014). Here we described a method to isolate in both wild type and in mdx dystrophic muscle pure population of FAPs by double selection for SCA-1 and PDGFR $\alpha$ positivity in absence of the satellite cell markers SM/C2.6 and $\alpha 7$ integrin as well of the pan-lymphocytes marker CD45 or endothelial marker CD31.

\section{Material and Reagents}

1. 8-10 weeks old mice C57BL/6J wild-type mice (Charles River Laboratories International, http://www.criver.com) and mdx-4cv mice (B6Ros.Cg-Dmdmdx-4cv/J, crossed on C57/BL/6 background; Jackson ImmunoResearch Laboratories)

Note: Animals were treated in accordance with European Community guidelines and with the approval of the Institutional Ethical Committee.

2. Collagenase II (Worthington Biochemical, catalog number: CLSS2) 
3. Dulbecco's modified high glucose Eagle's medium (DMEM high glucose) (EuroClone, catalog number: ECB7501L)

4. $100 \mathrm{U} / \mathrm{ml}$ penicillin and $100 \mu \mathrm{g} / \mathrm{ml}$ streptomycin (EuroClone)

5. L-glutammine (EuroClone)

6. Recombinant human basic fibroblast growth factor (b-FGF) (Pepro Tech, catalog number: 100-18B)

7. Growth factor reduced BD Matrigel ${ }^{\mathrm{TM}}$ Matrix (BD Biosciences, catalog number: 356230)

8. Foetal Bovine Serum (FBS) (EuroClone)

9. Sterile phosphate buffered saline (PBS) w/o $\mathrm{Ca}^{++} \mathrm{Mg}^{++}$(EuroClone)

10. Antibodies

a. Anti-CD31-phycoerythrin/Cy7 (anti-CD31-PE/Cy7, clone 390) (eBioscience, catalog number: 25-0311)

b. Anti-CD45-PECy7 (clone 30-F11) (eBioscience, catalog number: 15-0451)

c. Anti-SM/C2.6-Biotin (kindly provided by Dr. Fukada) (Fukada et al., 2004)

d. Streptavidin-PE (BioLegend)

e. Anti- $\alpha$ 7-Integrin-PE (clone R2F2) (AbLab Laboratorio di Istologia e Citologia Patologica Veterinaria, catalog number: AB10RS24MW215)

f.Anti-PDGFRa-allophycocyanin (APC, CD140a, clone APA5) (BioLegend, catalog number: 135907)

g. Anti-LY-6A/E SCA-1-allophycocyanin/Cy7 (APC/Cy7, clone B7) (BD Biosciences, catalog number: 560654)

h. 7-aminoactinomycin D (7-AAD) (Life Technologies, catalog number: A1310)

11. Growth medium (GM) (see Recipes)

12. Wash buffer (WB) (see Recipes)

13. Collagenase II solution (see Recipes)

14. Erythrocytes lysis buffer (see Recipes)

Note: Use $1 \mathrm{ml}$ of this solution for approximately $1 \mathrm{~g}$ of muscle.

15. Sorting buffer (see Recipes)

16. Matrigel solution (see Recipes)

17. b-FGF solution (see Recipes)

\section{Equipment}

1. Scissors and tweezers

2. Cell culture plastic dishes (Corning, $\operatorname{Costar}^{\circledR}$ )

3. Six multiwells (Corning, Costar $^{\circledR}$ )

4. Centrifuge 
5. 50 and $15 \mathrm{ml}$ plastic tubes

6. $18 \mathrm{G}-10 \mathrm{ml}$ syringes

7. $70 \mu \mathrm{m}$ and $40 \mu \mathrm{m}$ cell strainer caps (BD Biosciences)

8. Beckam Coulter Cell Sorter MoFlo ${ }^{\mathrm{TM}}$ XDP (Beckman Coulter, catalog number: ML99030)

9. Cell culture incubator at $37{ }^{\circ} \mathrm{C}$ and $5 \% \mathrm{CO}_{2}$

10. Microscope or cell counter

\section{Procedure}

1. Sacrifice the mice (C57BL/6 or MDX) by delivering increasing concentrations of $\mathrm{CO}_{2}$ and remove hindlimb muscles.

2. Weigh the muscle mass.

3. Leave them in cold PBS-containing dish.

4. Remove visible tendon, adipose tissue and vessel.

5. Mince the muscles on new dish (not containing PBS) using a curved tip scissor for few minutes until the tissue appears like a mush.

6. Transfer the tissue into a $50 \mathrm{ml}$ plastic tube and add $0.2 \%$ collagenase II in DMEM (serum-free). Volume to use is $2-4 \mathrm{ml}$ of collagenase for $1 \mathrm{~g}$ of muscle weight: Usually each mouse allows obtaining 1-1.5 $\mathrm{g}$ of tissue. Put plastic tubes into a shaking thermostatic bath, at $37^{\circ} \mathrm{C}$ for $1 \mathrm{~h}$.

7. Separate undigested from digested material by centrifugation at $500 \mathrm{rpm}$. All the centrifugations are at room temperature. Supernatant (digested material) was removed, diluted with room temperature PBS (approximately $50 \mathrm{ml}$ of PBS/1 g muscle) and go through a $18 \mathrm{G}-10 \mathrm{ml}$ syringe to create a single cell suspension (about 10 passages through the needle).

8. Add to the un-digesting muscle fresh collagenase solution (using the same volume of step 6) and leave in the shaking thermostatic bath, at $37^{\circ} \mathrm{C}$ for additional $30 \mathrm{~min}$. Then, repeat step 7. Discard eventually indigested material that may remain after the second centrifugation procedure.

9. Muscle slurries obtained by the two digestions were pulled and filtered through $70 \mu \mathrm{m}$ cell strainer cap and subsequently through $40 \mu \mathrm{m}$ cell strainer cap, using $50 \mathrm{ml}$ syringes and $50 \mathrm{ml}$ plastic tubes.

10. Centrifuge at 2,000 rpm for $10 \mathrm{~min}$ and remove supernatant using a pipette.

11. Eliminate blood red cells by re-suspending cell with 1-2 $\mathrm{ml}$ of erythrocyte lysis buffer.

12. Dilute erythrocyte lysis buffer by addiction of $50 \mathrm{ml}$ of PBS containing $2 \% \mathrm{FBS}$ and centrifuge 2,000 rpm for $10 \mathrm{~min}$ at room temperature.

13. After removing the supernatant, using a pipette, add $1 \mathrm{ml}$ PBS containing $10 \%$ of FBS 
and count the cells.

14. Centrifuge tubes $2,000 \mathrm{rpm}$ for $10 \mathrm{~min}$ and incubate recovered cells for $30 \mathrm{~min}$ with anti$\mathrm{SM} / \mathrm{C} 2.6-$ Biotin on ice. Use $1 \mu \mathrm{l}$ of antibodies for $1 \times 10^{6}$ cells in $100 \mu \mathrm{l}$ of PBS containing $2 \%$ of FBS.

15. Add $1 \mathrm{ml}$ wash buffer and centrifuge 2,000 rpm for $5 \mathrm{~min}$.

16. After removing the supernatant, incubate on ice for $30 \mathrm{~min}$ with Streptavidin-PE and with the other labeled antibodies [anti-CD31-PECy7 and anti-CD45-PECy7, anti- $\alpha 7-$ IntegrinPE (for MDX mice), anti-PDGFRa-APC, anti-LY-6A/E SCA-1-APC/Cy7] and with 7aminoactinomycin D. As in step 14, use $1 \mu \mathrm{l}$ of antibodies for $1 \times 10^{6}$ cells in $100 \mu \mathrm{l}$ of PBS containing $2 \%$ of FBS.

17. Add $50 \mathrm{ml}$ of wash buffer and centrifuge $2,000 \mathrm{rpm}$ for $5 \mathrm{~min}$.

18. After removing the supernatant, add $2 \mathrm{ml}$ of sorting buffer/mice.

19. To set up the instrument, sample of about 50-100,000 cells were in parallel individually stained with the each single antibody or with 7-aminoactinomycin (single staining for compensation) in the same conditions of samples to sort. A sample of 50-100,000 cells was also no incubated with any antibody (unstained control). After $30 \mathrm{~min}$, add $1 \mathrm{ml}$ of wash buffer then centrifuge (2,000 rpm for $5 \mathrm{~min}$ ). Remove supernatant and add 200$300 \mu$ of PBS containing $2 \%$ of FBS

20. For cell sorter setting: Using unstained control, exclude debris and dead cells by forward scatter and side scatter and set basal fluorescence (Figure 1A). Then make 7-AAD gating using sample stained with 7-aminoactinomycin (gate 1, 7AAD negative cells and gate 2) to further eliminate dead ells.

21. Compensate fluorescence using the samples individually stained with each antibodies and then select in sample to sort FAP cells as CD45/CD31- (gate 3)/smc2.6- or a7integrin- (gate 4)/SCA-1+ and PDGFRa ${ }^{+}$(gate 5) cells. To improve purity, we preferred to employ anti- smc2.6 for WT mice and anti- $\alpha 7$ integrin for $m d x$ mice.

22. At the end of sorting, plate FAP cells at $1 \times 10^{4} \mathrm{cells} / \mathrm{cm}^{2}$ in multiwell plates previously coated with Matrigel and culture for 6 days in growth medium plus b-FGF in a humidified incubator $\left(37^{\circ} \mathrm{C}\right.$ and $\left.5 \% \mathrm{CO}_{2}\right)$. 


\section{Representative data}
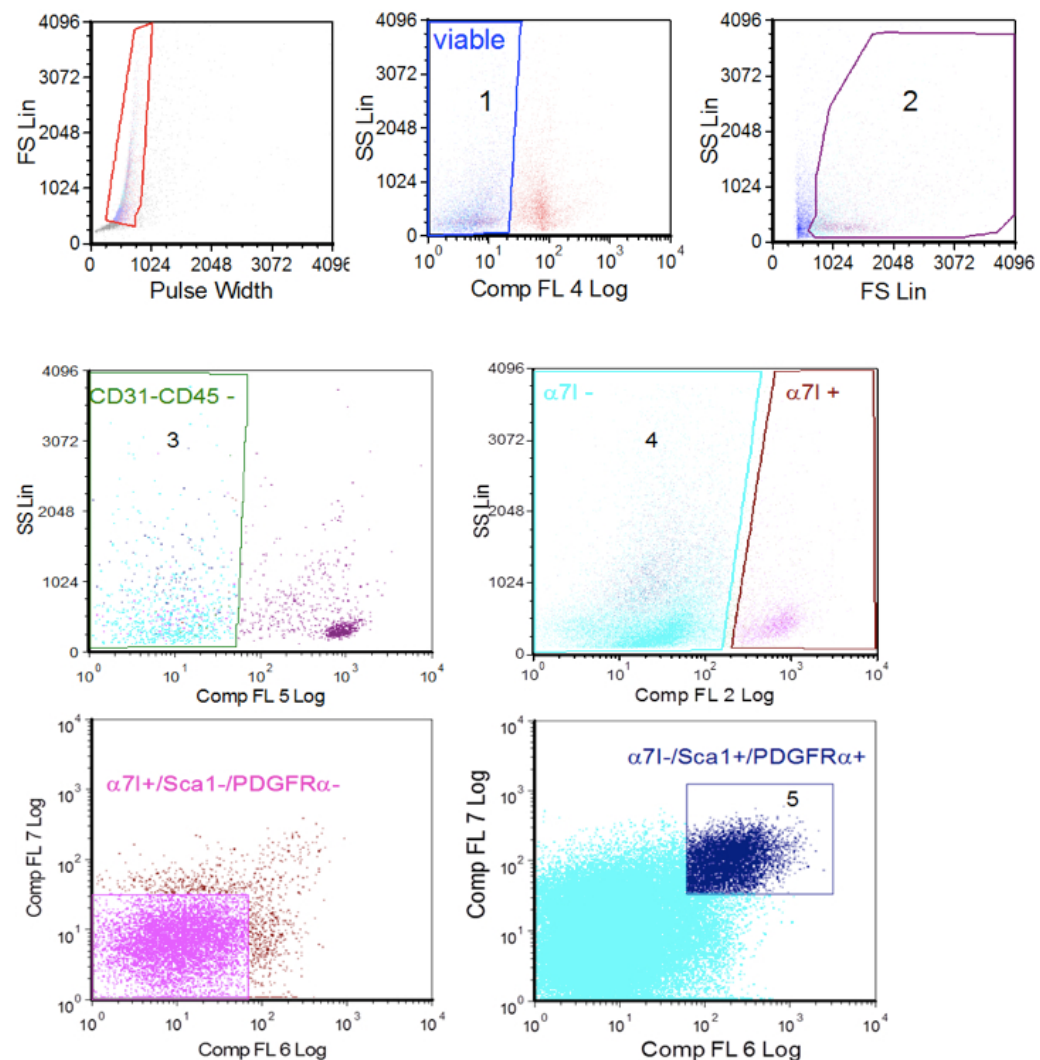

Figure 1. Cell sorter procedure. A. single cells gating; B. viable cells gating based on selection of 7ADD negative cells (1, left) and forward scatter/side scatter parametes (2, right); C. CD31 and CD45 negative cells gating (3); D. $\alpha 7$-integrin gating (4); E. satellite cells gating (Sca 1/PDGFR $\alpha$ negative cells from $\alpha 7$-integrin positive gate); F. FAP cells gatining (ScA 1/PDGFRa positive cells from the $\alpha 7$-intergrin negative gate (5).

\section{Notes}

1. FAP cells recovery range from 1 to $3 \%$ of total cells. Digestion seems to be the critical point.

\section{$\underline{\text { Recipes }}$}

1. Growth medium (GM)

Dulbecco's modified high glucose Eagle's medium (DMEM) supplemented with heat inactivated $20 \%$ fetal bovine serum (FBS), $100 \mathrm{U} / \mathrm{ml}$ penicillin and $100 \mu \mathrm{g} / \mathrm{ml}$ streptomycin plus $5 \mathrm{ng} / \mathrm{ml}$ of recombinant human basic fibroblast growth factor 
2. Wash buffer (WB)

PBS w/o $\mathrm{Ca}^{++}$and $\mathrm{Mg}^{++}$with heat inactivated $2 \% \mathrm{FBS}$

3. Collagenase II solution

$0.2 \%$ collagenase solution was prepared in DMEM, filtered on a $0.2 \mu \mathrm{m}$ filter and immediately used.

4. Erythrocytes lysis buffer

$0.8 \% \mathrm{NH}_{4} \mathrm{Cl}$ in Tris-buffer $(\mathrm{pH} 8)$

5. Sorting buffer

PBS w/o $\mathrm{Ca}^{2+}$ and $\mathrm{Mg}^{2+}$ with $5 \%$ heat inactivated FBS

6. Matrigel solution

Dilute Matrigel 1:100 in DMEM and use immediately after preparation for plate coating

Left Matrigel working solution into the plate for 30 min before removing

Matrigel must not dry

7. b-FGF solution

Prepare $100 \mu \mathrm{g} / \mathrm{ml}$ stock solution aliquots and keep them at $20^{\circ} \mathrm{C}$

In culture b-FGF concentration was $5 \mathrm{ng} / \mathrm{ml}$

After defrosting, b-FGF aliquot could remain at $4{ }^{\circ} \mathrm{C}$ and used within a week

\section{Acknowledgments}

We are grateful to Prof. So-ichiro Fukada (Osaka University, Osaka, Japan) for the SMC/2.6 antibody. This work was supported by the European Community's framework program FP7/2007-2013 under grant agreement $n^{\circ} 241440$ (ENDOSTEM), the Italian Ministry of Health RC 2013, Associazione Italiana Ricerca sul Cancro (AIRC IG11362) and from the Ministero della Università e Ricerca PRIN 2010-2011.

\section{References}

1. Cordani, N., Pisa, V., Pozzi, L., Sciorati, C. and Clementi, E. (2014). Nitric oxide controls fat deposition in dystrophic skeletal muscle by regulating fibro-adipogenic precursor differentiation. Stem Cells 32(4): 874-885.

2. Fukada, S., Higuchi, S., Segawa, M., Koda, K., Yamamoto, Y., Tsujikawa, K., Kohama, Y., Uezumi, A., Imamura, M., Miyagoe-Suzuki, Y., Takeda, S. and Yamamoto, H. (2004). Purification and cell-surface marker characterization of quiescent satellite cells from murine skeletal muscle by a novel monoclonal antibody. Exp Cell Res 296(2): 245-255. 
3. Joe, A. W., Yi, L., Natarajan, A., Le Grand, F., So, L., Wang, J., Rudnicki, M. A. and Rossi, F. M. (2010). Muscle injury activates resident fibro/adipogenic progenitors that facilitate myogenesis. Nat Cell Biol 12(2): 153-163.

4. Natarajan, A., Lemos, D. R. and Rossi, F. M. (2010). Fibro/adipogenic progenitors: a double-edged sword in skeletal muscle regeneration. Cell Cycle 9(11): 2045-2046.

5. Uezumi, A., Fukada, S., Yamamoto, N., Takeda, S. and Tsuchida, K. (2010). Mesenchymal progenitors distinct from satellite cells contribute to ectopic fat cell formation in skeletal muscle. Nat Cell Biol 12(2): 143-152.

6. Uezumi, A., Ito, T., Morikawa, D., Shimizu, N., Yoneda, T., Segawa, M., Yamaguchi, M., Ogawa, R., Matev, M. M., Miyagoe-Suzuki, Y., Takeda, S., Tsujikawa, K., Tsuchida, K., Yamamoto, H. and Fukada, S. (2011). Fibrosis and adipogenesis originate from a common mesenchymal progenitor in skeletal muscle. J Cell Sci 124(Pt 21): 3654-3664. 